\title{
Axial and Radial Permeability Evolutions of Compressed Sandstones: End Effects and Shear-band Induced Permeability Anisotropy
}

\author{
Jeremie Dautriat, ${ }^{1,2}$ Nicolas Gland,${ }^{1}$ Jean Guelard, ${ }^{1}$ Alexandre Dimanov, ${ }^{2}$ and \\ JEAN L. RAPHANEL ${ }^{2}$
}

\begin{abstract}
The influence of hydrostatic and uniaxial stress states on the porosity and permeability of sandstones has been investigated. The experimental procedure uses a special triaxial cell which allows permeability measurements in the axial and radial directions. The core sleeve is equipped with two pressure samplers placed distant from the ends. They provide mid-length axial permeability measure as opposed to the overall permeability measure, which is based on the flow imposed through the pistons of the triaxial cell. The core sleeve is also equipped to perform flows in two directions transverse to the axis of the sample. Two independent measures of axial and complementary radial permeability are thus obtained. Both Fontainebleau sandstone specimens with a porosity of about $5.8 \%$ to $8 \%$ and low permeability ranging from $2.5 \mathrm{mD}$ to $30 \mathrm{mD}$ and Bentheimer sandstone with a porosity of $24 \%$ and a high permeability of $3 D$ have been tested. The initial axial permeability values obtained by each method are in good agreement for the Fontainebleau sandstone. The Bentheimer sandstone samples present an axial mid-length permeability 1.6 times higher than the overall permeability. A similar discrepancy is also observed in the radial direction, also it relates essentially to the shape of flow lines induced by the radial flow. All the tested samples have shown a higher stress dependency of overall and radial permeability than mid-length permeability. The effect of compaction damage at the pistons/sample and radial ports/sample interfaces is discussed. The relevance of directional permeability measurements during continuous uniaxial compression loadings has been shown on the Bentheimer sandstone until the failure of the sample. We can efficiently measure the influence of brittle failure associated to dilatant regime on the permeability: It tends to increase in the failure propagation direction and to decrease strongly in the transverse direction.
\end{abstract}

Key words: Directional permeability, end effects, permeability anisotropy, sandstone, shear band, stress dependency.

\section{Introduction}

It is well known that the decrease of pore pressure due to oil production induces changes of the field stress state, and for instance it increases the effective vertical and horizontal stresses applied on the reservoir (Holt, 1990; Schutuens and De Ruig, 1997). The compaction stemming from this stress increase modifies the structure and thus the petrophysical properties of the reservoir rocks. It is therefore of prime importance in

${ }^{1}$ Institut Français du Pétrole, 1\&4 avenue de Bois Préau, 92852 Rueil-Malmaison Cedex, France. E-mail: nicolas.gland@ifp.fr

${ }^{2}$ Laboratoire de Mécanique des Solides, CNRS, Ecole Polytechnique, 91128 Palaiseau Cedex, France. 
reservoir engineering to understand the interplay between stresses, porosity and permeability evolutions of the rocks. Many authors have pointed out the role of stress anisotropy for permeability and also for other structure-sensitive parameters (MORITA et al., 1992; Al-Harty et al., 1999). In a recent paper, HeILAND (2003) reviews numerous experimental studies of hydromechanical coupling and stress-dependent permeability.

In order to establish the dependency of the permeability of rocks on effective pressure, the most commonly used experimental set-up is a triaxial cell, which allows investigation of the effects of different stress paths, in hydrostatic (ZOBACK and BYERLEe, 1975; WALSH and Brace, 1984; Morrow et al., 1984; and others), deviatoric (Rhett and Teufel, 1992a,b; Wong et al., 1997; ZHU and WoNG, 1997) or uniaxial conditions (TRAUTweIn and Huenges, 2005). Owing to the geometry of a classical triaxial cell, some authors have acknowledged the importance of frictional effects at the piston/sample interfaces. However, these effects mostly have been documented in soil mechanic (LEE, 1978; FouRIE and XIAOBI, 1991; SHENG et al., 1997) rather than for consolidated geomaterials. Recently, KoRSNES et al. (2006) have investigated the influence of these end effects on permeability of both chalks and sandstones using a modified core sleeve, which allows pore pressure sampling in a region distant from the interfaces where frictional effects take place.

The anisotropic evolutions of permeability as a result of effective stress increase are also a fundamental issue in reservoir engineering. In most cases, the oil recovery rate is closely related to horizontal permeability, which is sensitive to changes of the vertical stress. Therefore, flow experiments should be performed under deviatoric stress states. Besides, the geometry of the sample must be adapted in order to minimize end effects and to allow independent measurements of axial and radial permeabilities. Anisotropic permeabilities in porous sandstones under non-hydrostatic stress states were measured by Zoback and Byerlee (1975), Bruno (1994) and Zhu et al. (1997). The authors used triaxial compression and extension tests with conventional triaxial cells and measured the permeabilities along the maximum and minimum principal stresses. Conversely, Schutjens and De Ruig (1997) have utilized a true triaxial cell to perform fluid flows along the minimum principal stress.

In this paper we present new experiments performed with a special triaxial cell designed to operate under temperature and pressure conditions representative of reservoir rocks and allowing simultaneous measurements of deformation, porosity and directional permeability evolution. Two different sandstones have been studied: A tight Fontainebleau sandstone with a low permeability and a permeable Bentheimer sandstone. Axial and radial permeability measurements are presented and discussed for both materials. We focus on suspected end effects, which we investigate by FEM calculations.

\section{Experimental Set-up and Procedure}

Axial and two perpendicular radial measurements of flows and pore pressures are the most innovative features of the apparatus designed for this study (see Fig. 1). Two high 

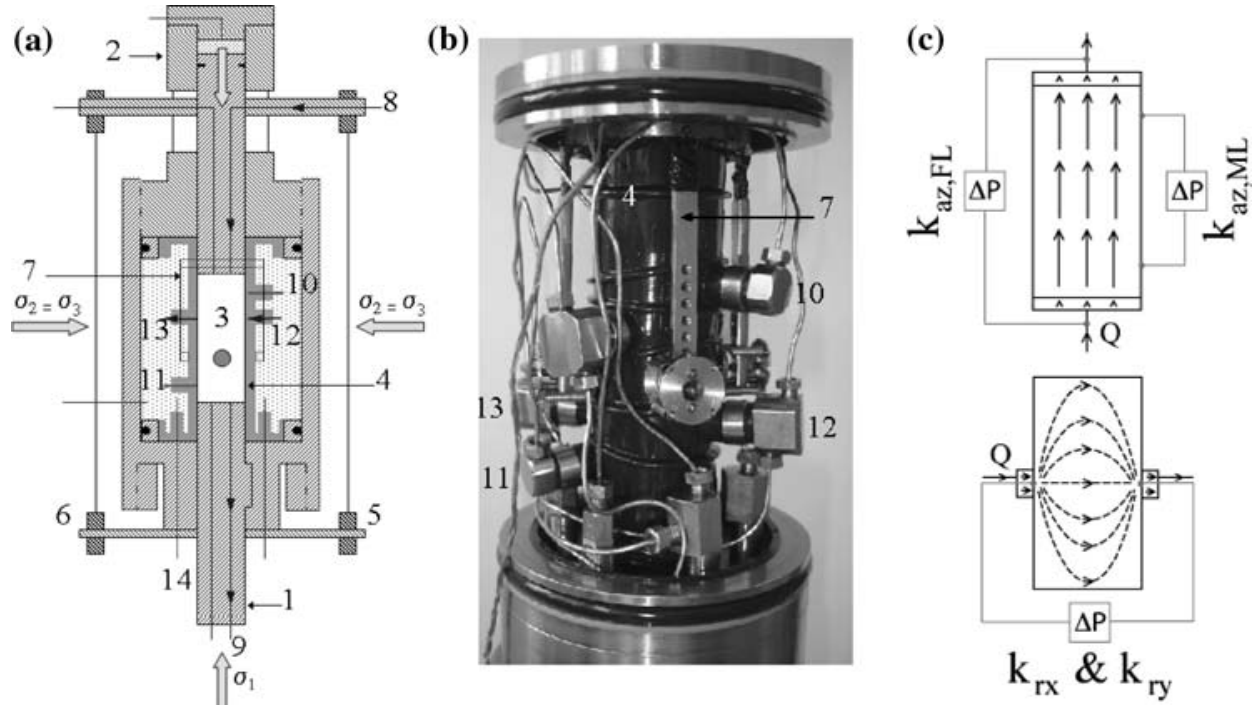

Figure 1

(a) Simplified sketch of the triaxial cell, (b) picture of the equipped core sleeve, (c) pressure differential and flow configurations for permeabilities $\mathrm{k}_{\mathrm{az}, \mathrm{FL}}, \mathrm{k}_{\mathrm{az}, \mathrm{ML}}$ and $\mathrm{k}_{\mathrm{rxy}}$; item numbers refer to: (1) fixed piston, (2) mobile piston, (3) sample, (4) sleeve, $(5,6)$ external LVDT, (7) internal cantilever, $(8,9)$ axial flow lines, $(10,11)$ pore fluid pressure samplers, $(12,13)$ radial flow ports, $(14)$ external flow lines connectors.

pressure Isco pumps control independently axial load and confining pressure $\left(P_{c}^{\max }=69\right.$ $\mathrm{MPa})$. An intermediate pressure Isco pump either generates a brine flow through the sample or regulates the pore pressure $\left(P_{p}^{\max }=25 \mathrm{MPa}\right)$. Since temperature fluctuations affect the pore fluid viscosity, a temperature regulation is provided by placing the cell in an oven (regulated up to a maximum temperature of $200^{\circ} \mathrm{C}$ ) and also by regulating the temperature of the pore fluid in the pump and outside lines by a thermostated bath and heating resistances, respectively. All the results presented in this paper are obtained at a temperature of $40^{\circ} \mathrm{C}$, low limit for accurate temperature regulation of the oven. The triaxial cell is also equipped with deformation sensors to measure both axial and radial deformations of the sample. The axial displacement of the upper mobile piston is recorded by two external high temperature LVDT sensors from RDP. The radial deformations of the core are measured using a double cantilever sensor from ERGOTECH fastened on the core sleeve inside the cell. The dimensions of the sample are $38.1 \mathrm{~mm}$ in diameter and $80 \mathrm{~mm}$ in length.

The most important innovation of our experimental setup is the special core sleeve which allows flows generation and differential pressure measurements along the core diameter. Generally, permeability evolution of a sample subjected to deviatoric stresses is measured along the direction of the maximal stress, by sampling the pressure differential between the inlet and the outlet of the sample. Additionally, with our setup, we can sample the differential pressure between two points $60 \mathrm{~mm}$ apart and located at $\sim 10 \mathrm{~mm}$ 
from each end of the sample, using two pressure samplers (items 10 and 11 on Fig. 1) placed at the contact of the lateral sample surface. This alternative way to measure axial permeability avoids end-effects linked to the contacts between the sample and pistons which will be discussed in a following section.

The radial permeability is measured by two pairs of injector-receptor ports (items 12 and 13 on Fig. 1) facing each other, positioned along two orthogonal diameters and in two distinct planes. Each injector is made of a perforated PEEK plastic head (diameter $9 \mathrm{~mm}$ ) for the fluid injection at the surface of the sample fitted with a coaxial Hastelloy tube (diameter 1/16 in) for pressure measurement. In addition, to allow a better flow distribution at the inlet and the outlet of the sample surface, Al316 fiber discs with average mesh aperture of $25 \mu \mathrm{m}$ are placed at the contact of the sample.

In order to measure the differential pressure induced by fluid flow through the sample, we use a set of differential pressure sensors from ABB from \pm 15 mbar to \pm 400 mbar adapted to measure the permeability of cores of $1 \mathrm{D}$ to $1 \mathrm{mD}$. All the measurable parameters are monitored on an acquisition bench and recorded on a computer.

The cylindrical samples are cored perpendicularly to the supposed stratification according to the quarry block extraction information (no evidence of bedding planes on the block sides). They are then dried during 48 hours. Their dry weight and exact dimensions are recorded, and then they are placed under low vacuum for 5 hours. The samples are then saturated by $\mathrm{NaCl}$ brine of concentration $20 \mathrm{~g} \cdot \mathrm{l}^{-1}$ (commonly recommended salinity in core analysts community to prevent clays alteration), and from the saturated weight we determine the initial porosity. The saturated sample is placed into the instrumented sleeve; the cell is closed, filled with the confining oil, and the upper piston is brought in contact with the sample. At this stage, confining and axial pressures of a few MPa are applied to ensure the sealing of the sleeve. Fluid circulation is established through the system to saturate the lines and to evacuate residual gas bubbles, and the pore fluid pressure is brought at $1 \mathrm{MPa}$ and regulated by a back-pressure system. This low effective pressure limits microbubbles trapping, and insures an efficient liquid permeability measurement; it also allows starting experiments at an initial low hydrostatic pressure. The oven, the pore fluid pump and the external flow lines are then regulated to $40^{\circ} \mathrm{C}$. Thermal stabilization is achieved in a few hours for the cell and a few minutes for the pump. At this stage the displacement sensors are set to zero.

Two kinds of compression stress paths are performed in this study with pore pressure kept at $1 \mathrm{MPa}$. For hydrostatic loading some experiments are made stepwise, the pressure being increased by increments of $2 \mathrm{MPa}$ at low pressure and $5 \mathrm{MPa}$ to $10 \mathrm{MPa}$ at higher pressure. Others tests consist of a continuous loading with an increase rate of confining pressure fixed between $0.05 \mathrm{MPa} \cdot \min ^{-1}$ and $0.1 \mathrm{MPa} \cdot \mathrm{min}^{-1}$, low enough to be close to quasi-static conditions (HEILAND and RAAB, 2000). Deviatoric loadings are performed at a low confining pressure of $3 \mathrm{MPa}$, which insures the sealing of the sleeve, while a "uniaxial" stress state is imposed.

The porosity evolutions and the deformations of the samples are recorded during stress increase. The porous media is only connected to the thermostated Isco pump and 
pore pressure is regulated at $1 \mathrm{MPa}$. Hence, the variation of the pore volume of the core is directly related to the variation of the fluid volume inside the pump. The data recorded by the deformation sensors allow both the evaluation of strains and the control of the time necessary to reach compaction equilibrium. The porosity values can thus be determined precisely allowing for the total sample strains.

The axial and radial permeability measurements are based on the steady-state method. At each constant pressure step we perform 4 sets of differential pressure measurements ( 2 axial and 2 radial), each of them lasting about one hour. For each measurement we check for the validity of the Darcy law (laminar flow regime), by performing a sequence of 5 increasing flow rates and measuring the corresponding increasing pressure differential. Permeability is finally calculated from the slope of a linear regression as described in the following section.

All the measurements at each pressure step last about a day, consequently a complete loading sequence of one sample takes about two weeks. Unloading is implemented continuously from $65 \mathrm{MPa}$ to $3 \mathrm{MPa}$ at a small constant rate $\sim 0.1 \mathrm{MPa} \cdot \min ^{-1}$. The permeability after unloading is measured for comparison to the initial values.

\section{Permeabilities Calculation}

Permeability measurements are based on the steady-state method. Darcy's law is applied for the two axial measurements:

$$
\frac{Q}{A_{a}}=-\frac{k_{a z}}{\mu} \frac{\Delta P_{p}}{L}
$$

where $Q$ is the flow rate, $A_{a}$ is the cross section of the sample, $\mu$ is the fluid viscosity, $\Delta P_{p}$ is the pressure differential, and $L$ is the distance between the points of measurements. In the case of overall axial permeability measures $\left(k_{a z, F L}\right), L$ refers to the current length of the sample $(\mathrm{L} \sim 80 \mathrm{~mm})$; in the case of mid-length measures $\left(k_{a z, M L}\right), L$ refers to the spacing between the two pressure samplers $(\mathrm{L}=60 \mathrm{~mm})$.

For the two radial permeability measurements, a modified Darcy law is employed:

$$
\frac{Q}{A_{r}}=-G \frac{k_{r}}{\mu} \frac{\Delta P_{p}}{D},
$$

where $G$ is a geometrical factor introduced to account for the noncylindrical shape of the flow lines generated along the sample diameter $D$ by the radial flow ports of crosssectional area $A_{r}$. Such geometrical factor was first determined analytically by CoLLINS (1961) for a 2D transverse flow problem on a circular core, using a conformal mapping technique. More recently, BAI et al. (2002) calculated the geometrical factor using a finite-element model for a three-dimensional geometry of a transverse flow in cylindrical core. This is done using the equation: 
(a)

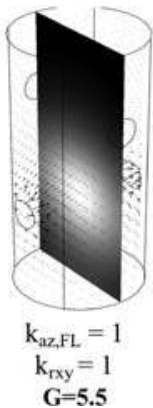

(b)

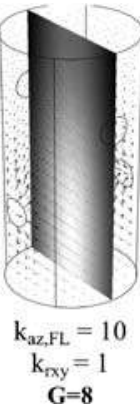

(c)

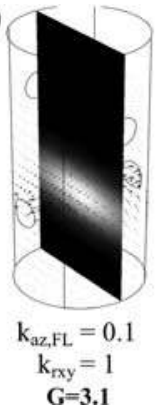

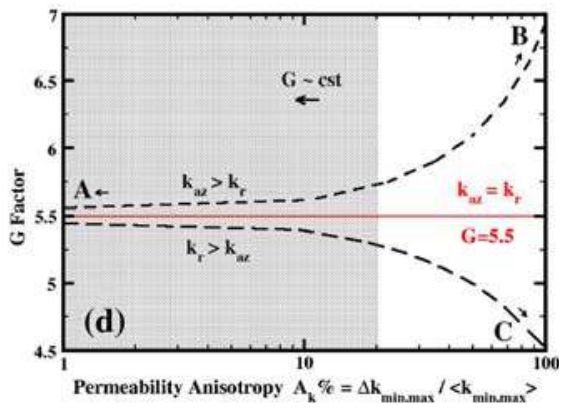

Figure 2

Geometrical model of the sleeve, radial velocity field and calculated Geometrical Factor $\mathrm{G}$ for different transverse permeability isotropy (a, A) $k_{\mathrm{az}}=\mathrm{k}_{\mathrm{r}}$, (b, B) $\mathrm{k}_{\mathrm{az}}>\mathrm{k}_{\mathrm{r}}$, (c, C) $\mathrm{k}_{\mathrm{az}}<\mathrm{k}_{\mathrm{r}}$; (d) evolution of G factor with the permeability anisotropy factor.

$$
G=\frac{\Delta P_{c y l}}{\Delta P_{p}}=\frac{A_{e q}}{A_{r}}
$$

where $\Delta P_{c y l}$ corresponds to the equivalent differential pressure generated by a flow through a cylinder with a cross-sectional area equal to $A_{r}$ (conventional case for Darcy's law application) and $A_{e q}$ is the unknown equivalent cross-sectional area of true 'ellipsoidal' flow.

For our specific experimental setup, the geometrical factor has been determined under the assumption of isotropy, using a finite-element simulation to solve the equation of flow at Darcy scale. The finite-element model is presented in Figure 2. Considering a sample of diameter $D=38.1 \mathrm{~mm}$ and length $L=80 \mathrm{~mm}$ and a radial port of diameter $d=9 \mathrm{~mm}$, we calculated a geometrical factor $G=5.5$ (see Fig. 2a). Nevertheless, it also remains critical to quantify the impact of permeability anisotropy on the transversal flow shape, and consequently on the geometrical factor value. Figure 2 illustrates the evolution of the geometrical factor with transversal isotropy. As clearly shown on Figures $2 \mathrm{~b}$ and $2 \mathrm{c}$, a variation of anisotropy ratio covering two orders of axial permeability magnitude induces roughly a factor 2.5 on the $G$ value. In addition, due to the low initial anisotropy of the studied sandstones, it seems acceptable to consider a constant value of 5.5 for the geometrical factor, for materials exhibiting an anisotropy factor less than $20 \%$ (see Fig. 2d).

In order to estimate the accuracy of the permeabilities calculation, the following accuracies have been used for the different variables:

- Common variables for all measurements: Volumic flow rate $u_{Q} \pm 1 \%$, viscosity $u_{\mu} \pm 2.5 \%$.

- Axial permeability variables: Core length $u_{L}$ (full-length case) $\pm 0.125 \%$ and $u_{L}$ (mid-length case) $\pm 0.25 \%$, injection area $u_{A a} \pm 0.5 \%$, pressure differential $u_{\triangle P p} \pm 1-2 \%$ (mostly dependent of $Q$ and the stability of flow). 
— Radial permeability variables: Diameter $u_{Q} \pm 0.25 \%$, injection area $u_{A r} \pm 2.2 \%$, differential pressure $u_{\triangle P p} \pm 5-10 \%$ (mostly dependent of $u_{a}$ and the stability of flow).

The accuracy calculation also integrates the error $u_{a}$ related to the slope of the linear regression $Q / \Delta P_{p}$, which is expressed as the quadratic sum of the regression component:

$$
u_{a}=\sqrt{\left.a^{2}\left(\frac{u_{Q}}{Q}\right)^{2}+\left(\frac{u_{\Delta P_{p}}}{\Delta P_{p}}\right)^{2}\right)+u_{r e g}^{2} a}+\hat{e}_{s y s},
$$

with $u_{\text {reg a }}^{2}$ the uncertainty related to the linear regression and $\hat{e}_{s y s}$ the systematic error related to the slope offset. Then, the estimated uncertainty of the permeability was calculated using the formula:

$$
u_{K}^{2}=\left(\frac{L a}{S}\right)^{2} u_{\mu}^{2}+\left(\frac{\mu a}{S}\right)^{2} u_{L}^{2}+\left(\frac{-\mu L a}{S^{2}}\right)^{2} u_{s}^{2}+\left(\frac{\mu L}{S}\right)^{2} u_{a}^{2} .
$$

This estimated uncertainty depends strongly on the differential pressure stability during the measurement. As discussed above, the differential pressure response of radial injection is generally noisier due to flow instability; and consequently, the radial permeability uncertainty is higher. Depending on experiments, the uncertainty on both axial permeabilities remains close to $\pm 5 \%$, whereas it ranges between $\pm 10-20 \%$ for the radial direction.

\section{Characterization of Fontainebleau and Bentheimer Sandstones}

Fontainebleau and Bentheimer sandstones (FS and BS) are well documented in the literature (see for instance Klein and Reuschlé, 2003 and Sulem and OufrRoukh, 2006b). Their composition is relatively simple and they have very different permeabilities, which is a reason why they have been selected in this study. The Fontainebleau samples have been cored from a single bar obtained in the core warehouse of I.F.P. and the Bentheimer samples have been cored from a single block from the quarry of Nordhern in Germany.

The Fontainebleau sandstone is made of more than 99\% quartz grains. The grain cohesion is provided by siliceous cement deposited by fluid flow during the diagenetic process (GRISONI and ThIRY, 1988). Scanning Electron Microscope (SEM) observations show a good sorting of the quartz grains around a grain size value of $250 \mu \mathrm{m}$. Figure $3 \mathrm{a}$ presents a typical microstructure recorded in Electron Back-Scattering mode. This technique allows detection of secondary phases. For instance, the light gray crystal in the central part of the figure is a rutile crystal that has indented a larger quartz particle during diagenesis. Most of the macroscopic measurable porosity value is due to large pores, which are interconnected by intergranular micro-channels (or throats) at the grains boundaries. As shown on Figure 3b, the mercury injection curves reveal a narrow distribution of throat radii around a value of $7 \mu \mathrm{m}$, but the SEM observations and the 

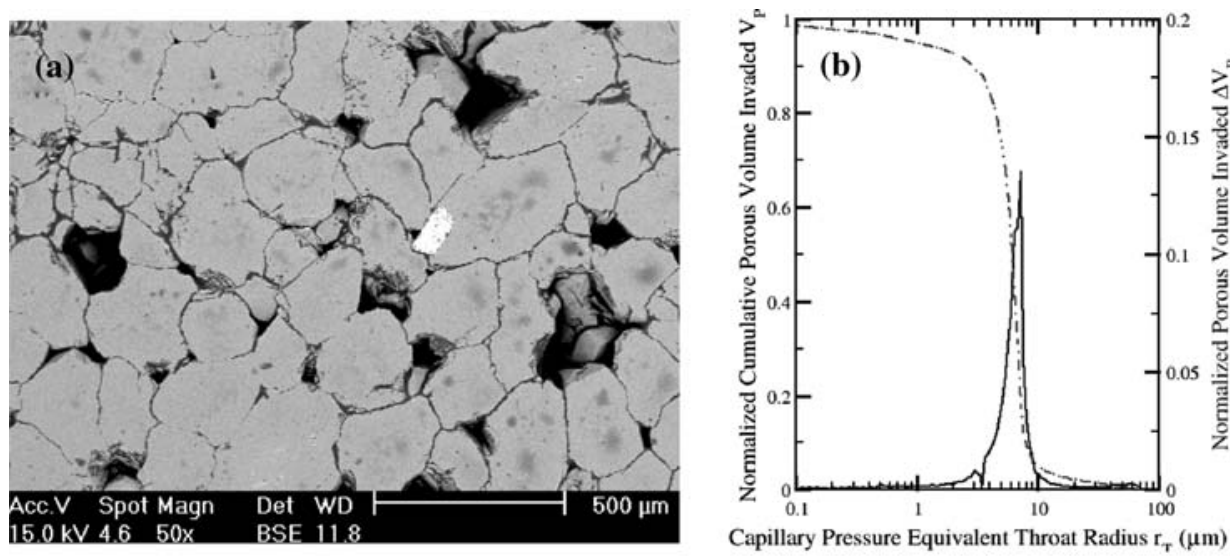

Capillary Pressure Equivalent Throat Radius $\mathrm{r}_{\mathrm{r}}(\mu \mathrm{m})$

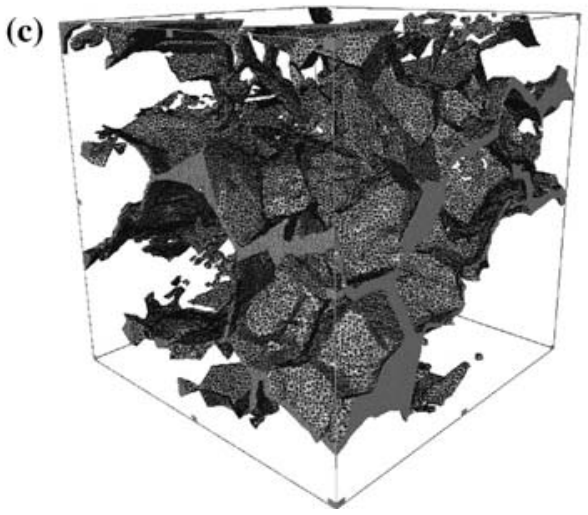

Figure 3

Microstructural characterization of Fontainebleau sandstone: (a) SEM Image in BSE mode, (b) Hg porosimetry (up to $400 \mathrm{MPa}$ ) and (c) pore volume extraction from a $1 \mathrm{~mm}^{3}$ microtomography volume.

micro-tomography reconstruction (see Fig. 3c) yield a value closer to $1 \mu \mathrm{m}$. This discrepancy is essentially due to the shape of the throats in the Fontainebleau sandstone far from the ideal cylindrical shape model used to calculate an equivalent pore throat radius for the Mercury capillary pressure curve.

The very large range of porosity values from $2 \%$ to $30 \%$ of Fontainebleau sandstones has been previously interpreted to result from spatial heterogeneities of the diagenetic fluid flows Bourbie and ZinszNer (1985). This extended range of porosity values leads to a large variation of the permeability. The two samples that we have tested present different porosities of $\sim 5.8 \%$ and $\sim 8 \%$, however their permeabilities differ by one order of magnitude, since it varies between $\sim 2.5 \mathrm{mD}$ and $\sim 30 \mathrm{mD}$ (see initial porosity and axial permeabilities, values measured with our experimental setup in Table 1).

The Bentheimer sandstone is composed of $95 \%$ quartz, a small fraction of altered feldspars (less than $2 \%$ ) and approximately of $3 \%$ clay homogeneously distributed in the 
Table 1

Petrophysical parameters of the tested Fontainebleau samples FS1 and FS2, measured at the initial and final stages of the hydrostatic loading and after unloading. The symbol-refers to improper conditions for permeability measurement (either unstable pressure differential or plugging of the flow/pressure ports) or for porosity measurement (leak on pore fluid lines)

\begin{tabular}{|c|c|c|c|c|c|c|}
\hline \multirow{2}{*}{$\begin{array}{l}\text { Sample } \\
\text { Pressure Level }\end{array}$} & \multicolumn{3}{|c|}{ FS1 } & \multicolumn{3}{|c|}{ FS2 } \\
\hline & $\begin{array}{c}\text { Initial at } \\
5 \mathrm{MPa}\end{array}$ & $\begin{array}{l}\text { Final at } \\
57 \mathrm{MPa}\end{array}$ & $\begin{array}{c}\text { Residual at } \\
5 \mathrm{MPa}\end{array}$ & $\begin{array}{c}\text { Initial at } \\
3 \mathrm{MPa}\end{array}$ & $\begin{array}{l}\text { Final at } \\
55 \mathrm{MPa}\end{array}$ & $\begin{array}{c}\text { Residual at } \\
3 \mathrm{MPa}\end{array}$ \\
\hline Porosity (\%) & 5.80 & 5.57 & 5.75 & 7.96 & 7.47 & - \\
\hline$k_{a z, F L}(\mathrm{mD})$ & 2.47 & 1.53 & 1.89 & 31.14 & 22.87 & 25.20 \\
\hline$k_{a z, M L}(\mathrm{mD})$ & 2.46 & 2.10 & 2.29 & 29.27 & 24.71 & 26.11 \\
\hline$k_{r x}(\mathrm{mD})$ & - & - & - & 19.60 & 8.11 & 9.64 \\
\hline$k_{r y}(\mathrm{mD})$ & 4.71 & $-(\rightarrow 3)$. & 3.19 & - & - & - \\
\hline
\end{tabular}

rock matrix. The quartz grains are well sorted around a value of $200 \mu \mathrm{m}$. Bentheimer sandstone exhibits larger permeability values $\left(\mathrm{k}_{\mathrm{az}, \mathrm{ML}} \sim 2.9 \mathrm{D}\right.$ and $\left.\mathrm{k}_{\mathrm{az}, \mathrm{FL}} \sim 1.5 \mathrm{D}\right)$ associated with one large porosity of about $24 \%$, and to a larger size of pore throats homogeneously distributed around $20 \mu \mathrm{m}$ as shown by the Mercury porosimetry curve in Figure 4. The feldspar alteration also contributes to the porosity connectivity. SEM investigations show that the intergranular contacts are narrower than for the Fontainebleau sandstone, hence the radii of throats are larger and consequently the permeability is substantially higher. Because the Bentheimer sandstone is quite homogeneous, permeability measurements were also performed on additional cores on a classical permeameter giving a permeability value of $\sim 1.6 \mathrm{D}$ close to the value obtained for the full-length axial permeability measured with our setup. The important discrepancy observed between the two methods of axial permeability measurements (full-length vs. mid-length) will be discussed in terms of end effects in a further section. Note that for the Fontainebleau sandstone, we did not have enough available material to plug additional samples of required dimension for measurement with the classical permeameter.

The difference of permeability between the two sandstones is in agreement with the observed shift of the pore throat radii distribution peek estimated from the $\mathrm{Hg}$ porosimetry. Indeed, since the local viscous dissipation varies as the power four of the characteristic dimension of the pore throats (hydrodynamic radius) and the pressure drops are located almost exclusively in the throats, the permeability is expected to follow roughly $k \propto \bar{r}_{t}^{4}$ and then $k_{B S} / k_{F S} \approx\left(\overline{r_{t, B S}} / \overline{r_{t, F S}}\right)^{4}$.

\section{Directional Permeability Evolutions under Hydrostatic Loading}

\subsection{Low Permeability Fontainebleau Sandstone}

The initial porosity values of the two tested samples of Fontainebleau sandstones FS1 and FS2 are respectively $5.8 \%$ and $8 \%$. The hydrostatic compression tests have been 

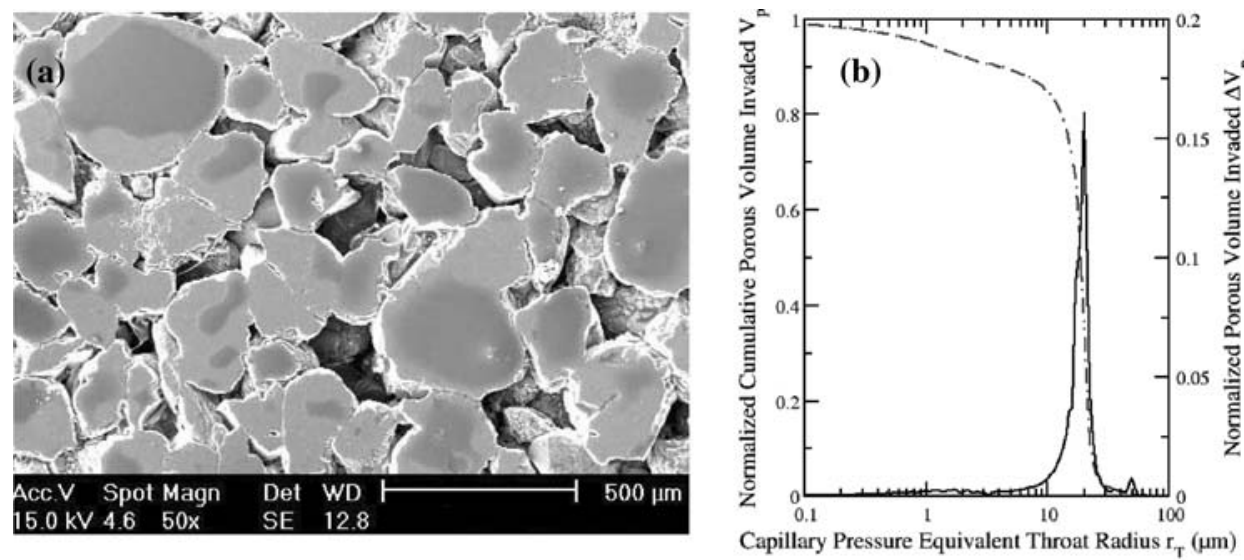

(c)

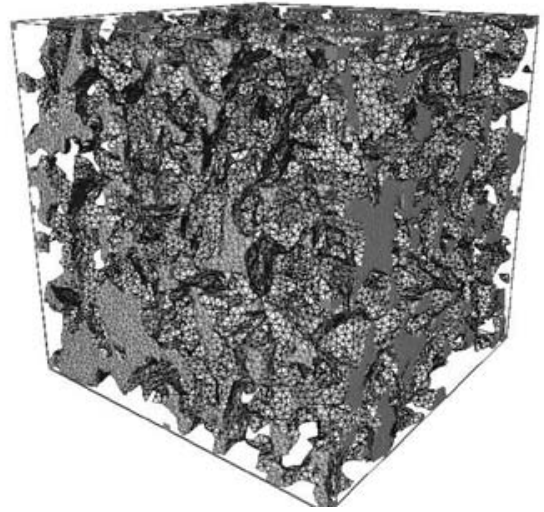

Figure 4

Microstructural characterization of Bentheimer sandstone: (a) SEM Image in SE mode, (b) Hg porosimetry (up to $400 \mathrm{MPa}$ ) and (c) pore volume extraction from a $6 \mathrm{~mm}^{3}$ microtomography volume.

started at low confining pressures, $\mathrm{P}_{\mathrm{c}}=6 \mathrm{MPa}$ for FS1 sample and $\mathrm{P}_{\mathrm{c}}=3 \mathrm{MPa}$ for FS2 sample, in order to ensure sealing of the core sleeve. At this stage we perform a first set of permeability measurements in each direction $\left(k_{a z, F L}^{0}, k_{a z, M L}^{0}, k_{r x}^{0}\right.$ and $\left.k_{r y}^{0}\right)$ reported in Table 1. Both full-length and mid-length axial permeability measurements are well correlated close to $2.5 \mathrm{mD}$ and $30 \mathrm{mD}$ for FS1 and FS2, respectively, whereas the radial permeability exhibits a higher value close to $4.7 \mathrm{mD}$ for FS1 and a lower value close to $19.6 \mathrm{mD}$ for FS2. This 'apparent' permeability anisotropy is in disagreement with the known homogeneity and low structural anisotropy of the Fontainebleau sandstone (Clavaud et al., 2008); this discrepancy seems mostly induced by fluctuations of radial flow conditions, as will be discussed further.

Despite the small porosity value differences between the two samples, we observe a high permeability variability in this porosity range, as previously described by BouRBIE 
and ZinSZNER (1985). The hydrostatic compression tests have been performed on the Fontainebleau Sandstone in a stepwise manner from the initial confining pressure up to $65 \mathrm{MPa}$. For each pressure step, the variation of porous volume and the strains of the sample are monitored. After an equilibration time for deformation, we measure the permeability in each direction using the protocol previously described.

In Figure 5, we present the porosity evolution inferred from the variation of porous volume measurements and also the absolute and normalized directional permeability evolutions with the mean effective pressure $\left(P_{\text {eff }}=P_{c}-P_{p}\right)$ obtained on the two Fontainebleau sandstone cores FS1 and FS2. In the following we consider the effective pressure nearly equal to the isostatic pressure, since the pore pressure remains constant at $1 \mathrm{MPa}$. By convention, the solid lines and open symbol represent the permeability in the axial direction $\mathrm{z}$, measured stepwise on the full sample length $k_{a z, F L}$ (circle) and on the middle length $k_{a z, M L}$ (square), whereas the dashed lines and full symbols represent the results obtained for the radial permeability $k_{r x}$ (triangle up) and $k_{r y}$ (triangle down).

The porosity decreases slightly from $5.80 \%$ to $5.57 \%$ for FS1 and from $7.96 \%$ to $7.47 \%$ for FS2. In a first stage of confining pressure up to $20 \mathrm{MPa}$ the porosity response is nonlinear, and then varies almost linearly up to $60 \mathrm{MPa}$ in both experiments. After unloading back to the initial pressure, the porosity of FS1 exhibits an hysteresis with a residual value of $5.75 \%$. The response of the Fontainebleau sandstone is therefore almost elastic with a nonlinear behavior in the early stage of the compression, characterized by a slight nonreversible deformation of the porous volume.

For the FS1 sample, the full-length axial permeability $k_{a z, F L}$ evolution shows a rapid decrease of $30 \%$ of the initial value $2.47 \mathrm{mD}$ until a pressure of $22 \mathrm{MPa}$. Above this pressure, which is commonly assumed to be the closure pressure of pre-existing microcracks (DAVID et al., 1994), the general trend becomes close to a slow linear decrease with a slope of $2.1 \mathrm{E}-3 \mathrm{MPa}^{-1}$. The minimum permeability reaches a value of $1.53 \mathrm{mD}$. After unloading, we measure a residual permeability of $1.89 \mathrm{mD}$. These results contrast with the evolution of the mid-length permeability $k_{a z, M L}$. Indeed, the trend of permeability loss remains linear with a slope of $3.1 \mathrm{E}-3 \mathrm{MPa}^{-1}$ during the complete loading. The absolute radial permeability exhibits a more pronounced linear response with a slope of $6.7 \mathrm{E}-3 \mathrm{MPa}^{-1}$ without evidence of a nonlinear response at the early stage of compression to reach a value of $3.27 \mathrm{mD}$ at $50 \mathrm{MPa}$. The last measurement at $57 \mathrm{MPa}$ could not be achieved.

Considering the results obtained on FS1, the hydrostatic compression test performed on FS2 is started at lower pressure $P_{c}^{0}=3 \mathrm{MPa}$ and we increased the number of loading steps to better identify the transition between the pseudo-elastic regime characterized by strong and nonlinear permeability drop and the elastic regime characterized by linear behavior.

As previously observed for FS1, axial full-length permeability $k_{a z, F L}$ strongly decreases from $31.14 \mathrm{mD}$ to $17.41 \mathrm{mD}$ at $30 \mathrm{MPa}$. However above this pressure the general trend is very difficult to define, because unexpectedly the permeability increases at $35 \mathrm{MPa}$ to reach $23.71 \mathrm{mD}$ and later follows a linear evolution with a 
FS1
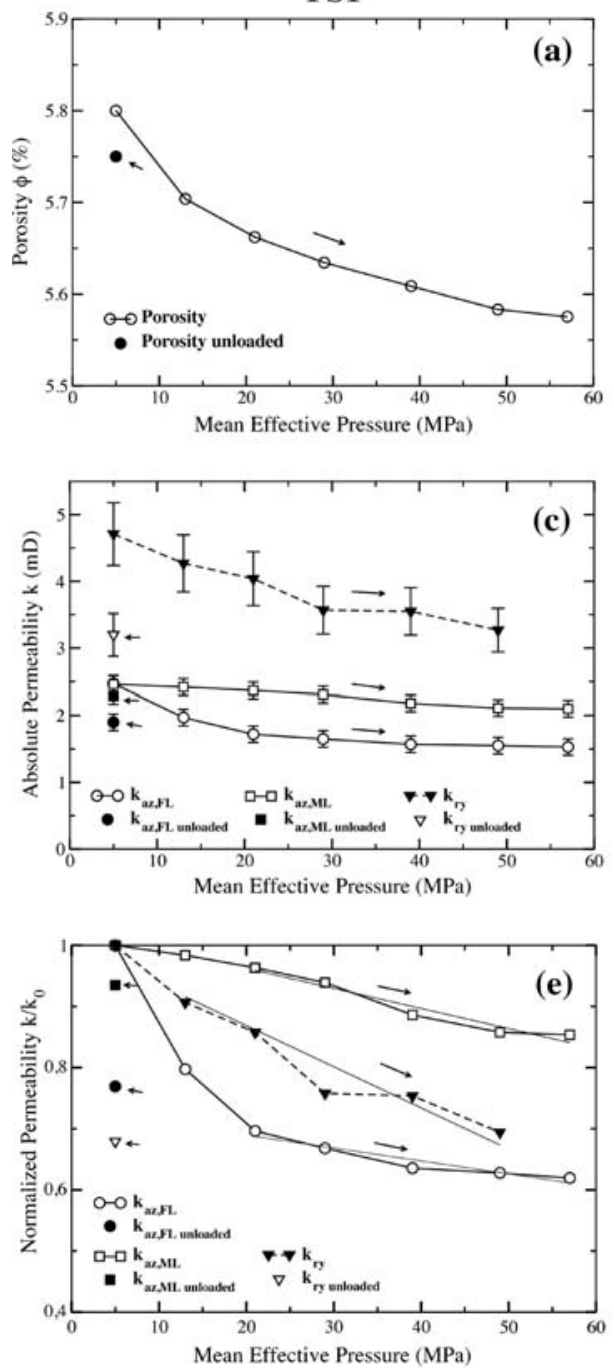

FS2
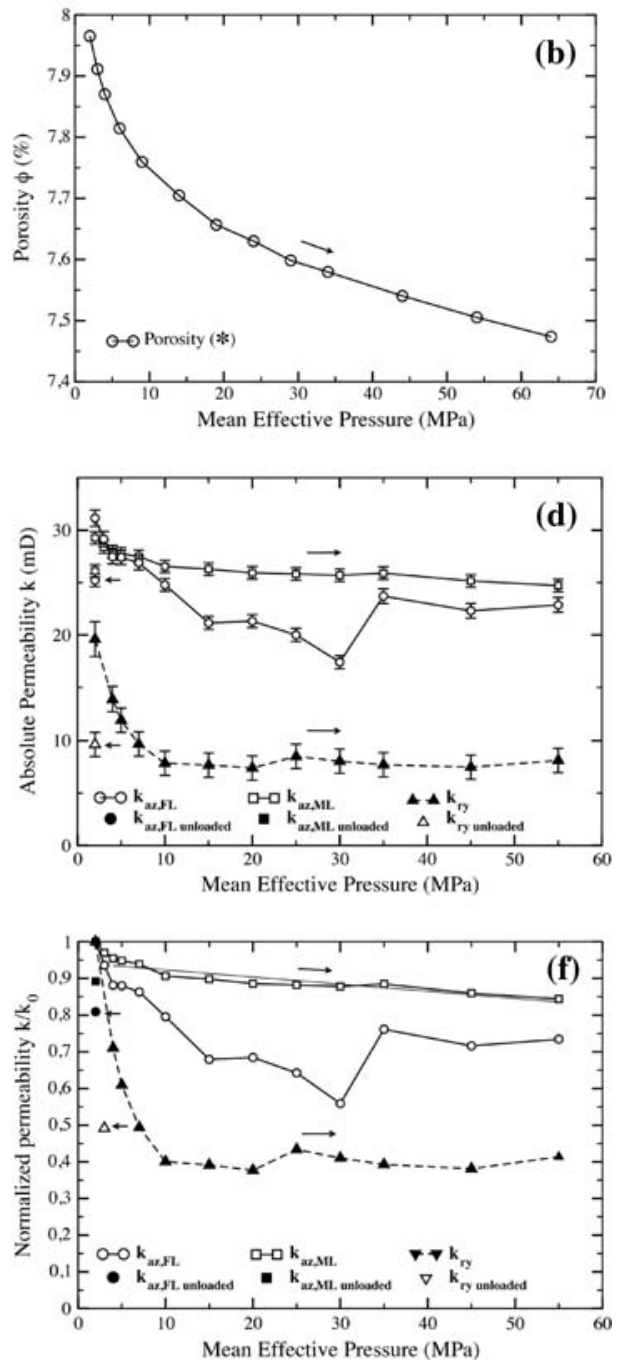

Figure 5

Porosity, absolute directional permeabilities and normalized directional permeabilities evolutions with the mean effective pressure for the FS1 (respectively (a), (c) and (e)) and FS2 (respectively (b), (d) and (f)) samples. Arrows show the loading/unloading paths; inverted filling properties of symbols refer to values at unloaded states (pressure decreased back to the initial value, $\mathrm{P}_{\mathrm{c}}=6 \mathrm{MPa}$ for FS1 and $\mathrm{P}_{\mathrm{c}}=3 \mathrm{MPa}$ for FS2); symbol * stands for: unloaded porosity value of FS2 sample could not be determinate due to a pump leak during the unloading.

slope of $1.95 \mathrm{E}-3 \mathrm{MPa}^{-1}$ up to $55 \mathrm{MPa}$. The mid-length axial permeability $k_{a z, M L}$, of initial value $29.27 \mathrm{mD}$, exhibits a weak diminution of almost $10 \%$ until $20 \mathrm{MPa}$, and records a total decrease of less than $15 \%$ at the final effective pressure of $55 \mathrm{MPa}$, with 
a permeability value of $24.71 \mathrm{mD}$. After unloading, the residual full-length and midlength axial permeabilities show close values of respectively $25.20 \mathrm{mD}$ and $26.11 \mathrm{mD}$.

The radial permeability $k_{r x}$ drops drastically from $19.60 \mathrm{mD}$ to $\sim 8 \mathrm{mD}$ during the first pressure steps up to $10 \mathrm{MPa}$. Above this pressure the permeability keeps more or less a constant value, given the error estimate. After unloading back to $\mathrm{P}_{\mathrm{c}}=3 \mathrm{MPa}$, the residual radial permeability value is equal to $9.64 \mathrm{mD}$.

\subsection{High Permeability Bentheimer Sandstone}

With Bentheimer sandstone we perform both stepwise and continuous hydrostatic loading experiments. The initial axial permeabilities $k_{a z, F L}^{0}$ and $k_{a z, M L}^{0}$ measured at $3 \mathrm{MPa}$ are respectively $1774 \mathrm{mD}$ and $2891 \mathrm{mD}$. Both axial measurements are expected to be approximatively the same, nonetheless we find the mid-length value to be $\sim 1.6$ time higher than the full-length value. A similar discrepancy also has been observed by KoRSNES et al. (2006), who used a corresponding experimental apparatus. The radial permeability $k_{r x}^{0}$ calculated with a Geometric Factor $G=5.5$ (equation (3)) yields an intermediate value of $2335 \mathrm{mD}$.

Figure 6 shows the evolution of the porosity with the increasing effective pressure. The porosity decreases from $24.4 \%$ to $23.6 \%$. As previously observed for the Fontainebleau sandstone, the porosity response is nonlinear until $20 \mathrm{MPa}$ and then evolves linearly up to $65 \mathrm{MPa}$. After unloading at $2 \mathrm{MPa}$, a pronounced hysteresis has been observed and the new residual porosity value is equal to $24.0 \%$. The superimposed continuous curve has been obtained from continuous loading cycles performed after unloading to $\mathrm{P}_{\mathrm{c}}=3 \mathrm{MPa}$.

On Figure 6 we also present the evolution of directional permeabilities acquired during both stepwise and continuous loading. The results obtained from stepwise loading show a moderate response of the permeabilities with the confining pressure increase, essentially due to rather high porosity and large pore throats of the Bentheimer sandstone. Indeed, the mid-length axial permeability only shows a slight decrease, less than $10 \%$ below $10 \mathrm{MPa}$. The full-length permeability shows a more pronounced decrease of almost $50 \%$ up to $20 \mathrm{MPa}$. From $20 \mathrm{MPa}$ to $65 \mathrm{MPa}$ this permeability decreases linearly with a slope of $2.14 \mathrm{E}-3 \mathrm{MPa}^{-1}$. The general trend of the radial permeability is not clear, nonetheless its evolution presents an intermediate behavior with high fluctuations. After unloading, we have measured the residual permeabilities $k_{a z, F L}^{r}, k_{a z, M L}^{r}, k_{r y}^{r}$ respectively equal to $1185 \mathrm{mD}, 2816 \mathrm{mD}$ and $2151 \mathrm{mD}$.

To limit differed local mechanisms of inelastic deformation for stress accommodation, which could influence the permeability measurements at constant confining pressure, we perform cycles of continuous loading with a rate of $0.1 \mathrm{MPa} \cdot \mathrm{min}^{-1}$. For instance, a similar procedure of continuous permeability measurements during triaxial loading is discussed by HEILAND and RAAB (2000). We have measured each continuous directional permeability during two cycles of loading/unloading, taking into account the axial and radial strains of the sample. As shown on Figure 6, the results obtained by this 

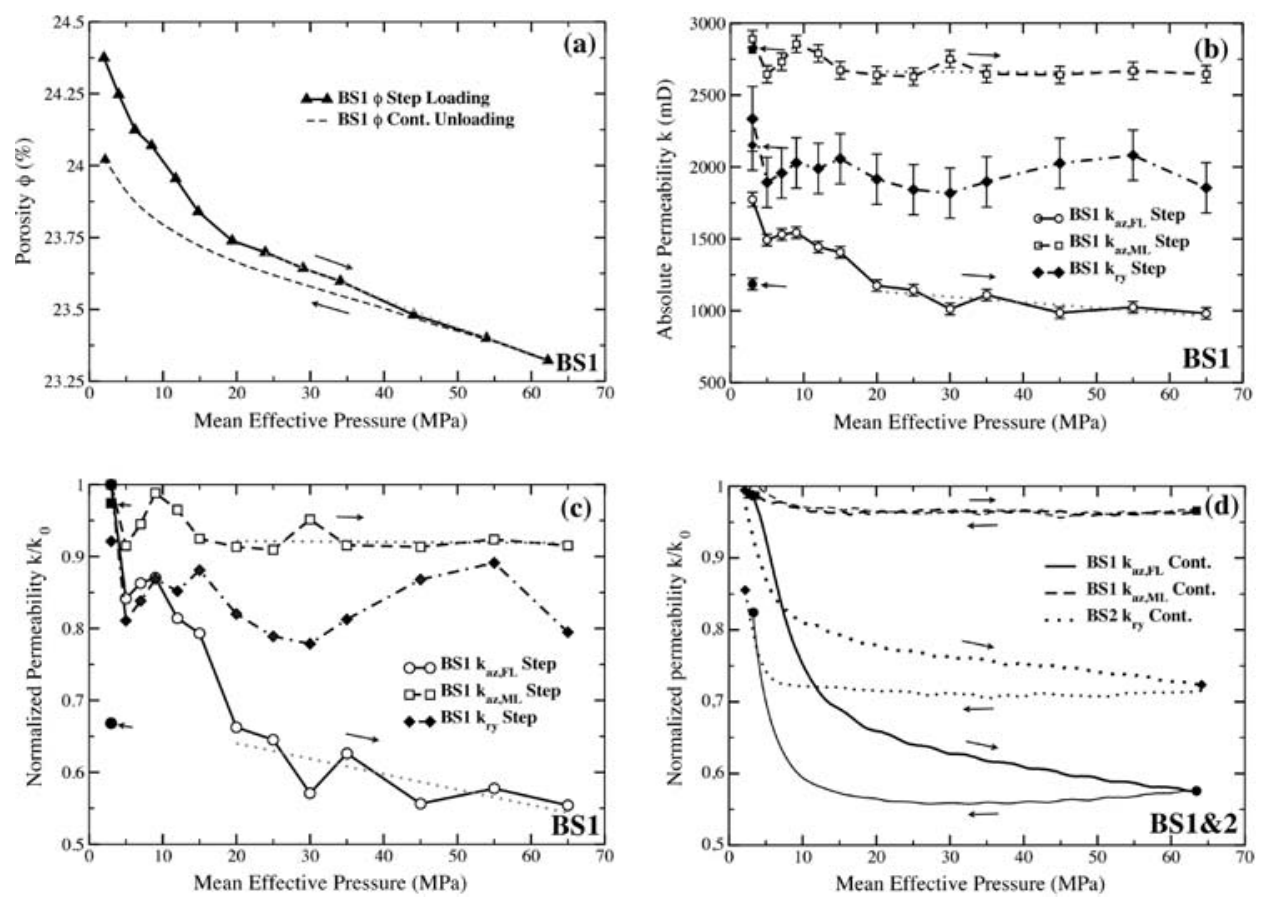

Figure 6

Evolutions of (a) porosity, (b) absolute directional permeabilities, (c) and (d) normalized directional permeabilities' evolutions during respectively ((a), (b), (c)) stepwise and (d) continuous hydrostatic compression tests. Arrows show the loading / unloading paths; inverted filling properties of symbols refer to values at the unloaded states (here, $\mathrm{P}_{\mathrm{c}}=3 \mathrm{MPa}$ ).

method are in good agreement with those obtained step by step and are less disrupted by experimental fluctuations. Those results confirm the loss of the permeability values $k_{a z, F L}$, $k_{a z, M L}$ and $k_{r y}$ of almost $40 \%, 10 \%$ and $25 \%$ observed during the first loading cycle. As previously pointed out, the permeability drop does not occur in the same range of pressure. Indeed, the most important drop is recorded up to $25 \mathrm{MPa}$ for $k_{a z, F L}, 10 \mathrm{MPa}$ for $k_{r y}$ and is negligible for $k_{a z, M L}$. Independently of the measurement direction, we also observe a delay in the permeability response during the sample unloading, most probably due to frictional effects.

\section{Directional Permeability Evolutions under "Uniaxial” Loading}

Transport properties of rocks are strongly influenced by the type of deformation regime. In this section we aim at characterizing the influence of shear-band generation and the importance of the evolutions of grain scale microstructures on the permeability anisotropy. We also highlight the ability of our apparatus to follow the directional 
response with regard to strong modification of microstructures. The uniaxial compressive strength of Fontainebleau sandstone exceeds the maximum axial stress accessible with our experimental setup, therefore we did not observe brittle failure of the sample and thus any major effects on the directional permeabilities. Hence, we only present the results of three experiments obtained on the Bentheimer sandstone.

We have performed deformation and directional permeabilities' measurements under continuous triaxial loading at low confining pressure. The principal objective is to be close to the true uniaxial conditions (i.e., without confining pressure), although the application of a low confining pressure $\left(P_{c}^{0}=3 \mathrm{MPa}\right)$ is necessary to insure an initial sealing of the core sleeve. The axial load is then continuously increased at a rate of $0.5 \mathrm{MPa} \cdot \mathrm{min}^{-1}$ until failure of the samples. During loading, pressure differential is monitored for each experiment in a given measurement direction and the directional permeabilities $k_{a z, F L}, k_{a z, M L}$ and $k_{r}$ are calculated on three different samples.

Prior to axial loading, a first set of permeabilities measurements is taken in each direction $\left\{k_{a z, F L}^{0}, k_{a z, M L}^{0}\right.$ and $\left.k_{r}^{0}\right\}$ (see Table 2) at hydrostatic condition. Again we observe differences within factors from 1.9 to 2.4 for both axial permeability measurements. Regarding the axial and radial permeability measurements, the full-length axial permeability is almost 1.9 times less than the radial permeability value.

As illustrated on Figure 7a, at first, axial full-length and radial permeabilities decrease steeply. Next, a nearly linear regime is observed up to $43 \mathrm{MPa}$ with slopes equal to 7.8 E-4 $\mathrm{MPa}^{-1}$ and $1.15 \mathrm{E}-3 \mathrm{MPa}^{-1}$ for axial full-length and radial permeability respec-

Table 2

Petrophysical parameters of the three Bentheimer samples BS1, BS2 and BS3, measured before and after the brittle failure at confining pressure of $3 \mathrm{MPa}$. For BS1 permeabilities'values, () refer to measurements before hydrostatic cycling. The symbol - refers to improper conditions for permeability measurement (either unstable pressure differential or plugging of the flow/pressure ports). The symbols $(\nearrow, \searrow, \rightarrow)$ refer respectively to the increase, the decrease or the stability of the permeability in the investigated direction

\begin{tabular}{|c|c|c|c|c|c|c|c|}
\hline Sample & \multicolumn{2}{|c|}{ BS1 $\left(k_{r x}^{c o n t}\right)$ (DAUTRIAT et al., 2009) } & \multicolumn{3}{|c|}{$\mathrm{BS} 2\left(k_{a z, F L}^{c o n t}\right)$} & \multicolumn{2}{|c|}{$\mathrm{BS} 3\left(k_{a z, M L}^{c o n t}\right)$} \\
\hline Porosity (\%) & \multicolumn{2}{|c|}{24.4} & \multicolumn{3}{|c|}{24.4} & \multicolumn{2}{|c|}{23.8} \\
\hline Initial State & \multicolumn{2}{|c|}{$\begin{array}{l}\text { Hydrostatic cycles } \\
\text { Pre-strained }\end{array}$} & \multicolumn{3}{|c|}{$\begin{array}{c}\text { No preliminary } \\
\text { hydrostatic cycling }\end{array}$} & \multicolumn{2}{|c|}{$\begin{array}{c}\text { No preliminary } \\
\text { hydrostatic cycling }\end{array}$} \\
\hline Permeability & $\begin{array}{l}k_{\text {init }} \text { at } \\
3 \mathrm{MPa}\end{array}$ & $\begin{array}{l}k_{C^{*}} \text { at } \\
3 \mathrm{MPa}\end{array}$ & $\begin{array}{l}k_{\text {init }} \text { at } \\
3 \mathrm{MPa}\end{array}$ & & $\begin{array}{l}k_{C^{*}} \text { at } \\
3 \mathrm{MPa}\end{array}$ & $\begin{array}{l}k_{\text {init }} \text { at } \\
3 \mathrm{MPa}\end{array}$ & $\begin{array}{l}k_{C^{*}} \text { at } \\
3 \mathrm{MPa}\end{array}$ \\
\hline $\mathrm{k}_{\mathrm{az}, \mathrm{FL}}(\mathrm{mD})$ & $\begin{array}{l}(1774) \\
1185\end{array}$ & 1560 & 1347 & $\longrightarrow$ & 1315 & 1234 & 1089 \\
\hline $\mathrm{k}_{\mathrm{az}, \mathrm{ML}}(\mathrm{mD})$ & $\begin{array}{l}(2891) \\
2816\end{array}$ & 2985 & - & - & - & 2826 & 2120 \\
\hline $\mathrm{k}_{\mathrm{rx}}(\mathrm{mD})$ & $\begin{array}{l}(2335) \\
2139\end{array}$ & 631 & 2571 & & 2244 & 2363 & 1667 \\
\hline $\mathrm{k}_{\mathrm{ry}}(\mathrm{mD})$ & $\begin{array}{l}(2811) \\
-\end{array}$ & - & 2620 & $\searrow$ & 2086 & 2097 & 1408 \\
\hline
\end{tabular}



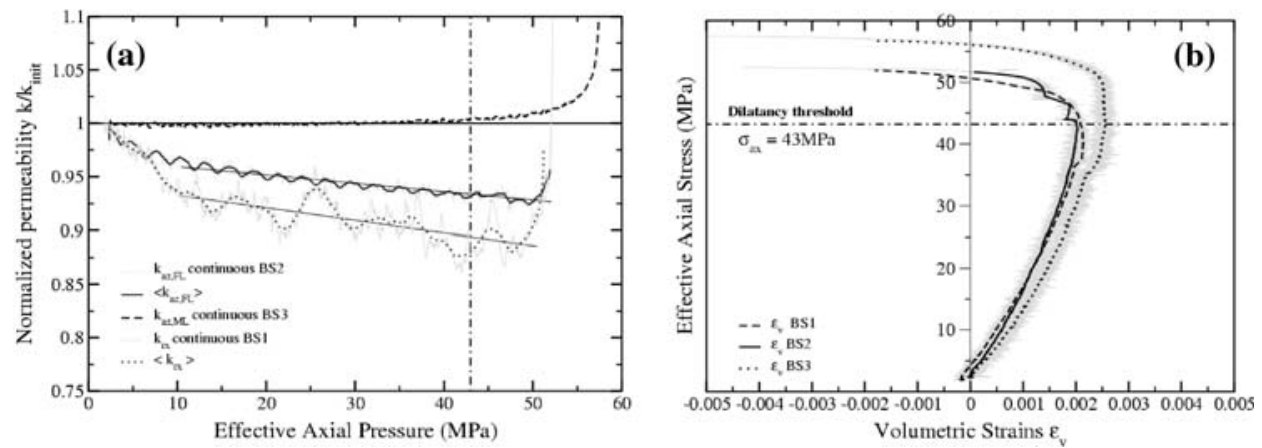

Figure 7

Evolutions of (a) directional permeability and (b) volumetric strains during continuous triaxial loading performed at low confining pressure $\left(\mathrm{P}_{\mathrm{c}}=3 \mathrm{MPa}\right)$ on three Bentheimer sandstone samples BS1, BS2 and BS3. The average dilatancy threshold occurring at axial stress of $\sim 43 \mathrm{MPa}$ is highlighted by dashed lines on the two figures.

tively. This stress corresponds to the dilatancy threshold (see Fig. 7b), and beyond this value one records an important increase of the permeability independently of the measurement directions. Note that the radial injection conditions might change locally, leading to fluctuations of the pressure differential between the radial inlet and outlet and hence to a noisier signal than the one obtained on the evolution of axial full-length permeability. After the failure point, the pressure differential strongly diverges and can no longer be related to permeability. The mid-length axial permeability follows a different trend without significant evolution until the dilatancy threshold, and increases sharply after this point.

The critical failure pressure $P_{C^{*}}$ is reached at $52.5 \mathrm{MPa}$ for the two first tested samples BS1 and BS2, whereas critical failure $P_{C^{*}}$ occurs at $57 \mathrm{MPa}$ for the last sample BS3; this higher strength could be explained by the fact that the last tested sample has not been subjected to hydrostatic loading cycles.

After failure, the axial stress is decreased back to its initial value and a new set of directional permeability is performed. The permeability values measured after unloading are presented in Table 2. Note that the geometrical factor $G$ used for the radial permeability is kept constant to 5.5 , and consequently the absolute permeability value could be significantly influenced by this approximation. In fact, it is the evolution of the differential pressure which actually provides qualitative information pertaining to the flow properties along the fracture. The full-length axial permeability of BS1 increases slightly by a factor of 1.3 , the mid-length is almost unaffected, and the radial permeability decreases strongly by a factor 3.4. From the measurements performed on BS2 and BS3, the failure induces a slight decrease of the axial permeability. Therefore, the radial permeability measurements present about $12 \%$ to $32 \%$ decrease from their initial values, according to the measurement direction.

In order to understand how the failure mode could affect the directional permeability values, the sample has been delicately taken out of the core sleeve and oriented with 

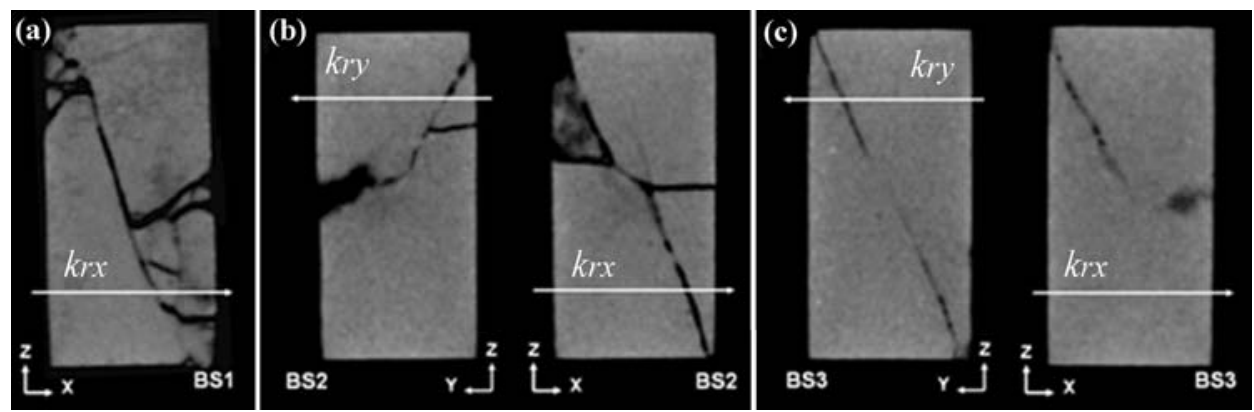

Figure 8

Tomography-RX slices of the Bentheimer sandstone samples (a) BS1, (b) BS2 and (c) BS3 subjected to 'uniaxial' compressions leading to brittle failure. The presented slices correspond to the planes in which the radial permeability measurement was performed.

respect to the injection directions and local pore pressure samplers positions. While the failure direction is clearly identified on the sample surface, we have performed CT-scan profiles of the sample along the three directions of performed flows. As shown on Figure 8, the principal shear band extends from the top to the bottom of the sample with a propagation angle close to $30^{\circ}$. The failure is also sub-perpendicular to the one of the radial injection direction. Several conjugated fractures are visible by tomographic analysis and their formation is probably related to the pressure control operation mode of our setup leading to the inability to control the post-peak behavior (i.e., after the dilatancy initiation). Our experimental setup does not allow the control of the strain rate applied on the sample, thus after brittle failure the radial axial stress still remains sufficient to further activate shear and to increase grain scale damage within the band.

It is known that the response in terms of porosity is highly related to the microstructure of the shear band (Vajdova et al., 2004). In a recent study, Sulem and OUFFROUKH (2006a) have shown by image processing analysis an increase of the porosity inside the band and minor grain crushing at low confining pressure. The authors related this observation to a dilating shear banding. The increase of the porosity in the band can explain the axial permeability increase, whereas the high permeability decrease recorded in the transverse direction of the band could be related to the important sliding of sample blocks along the band, associated with intensive grain crushing after post-peak. As clearly shown on Figure 8, we observe that the radial permeability decreases mostly where the flow lines intersect an intensively damaged zone.

\section{Discussion of the Experimental Results}

The permeability of numerous rock types has been extensively studied under hydrostatic conditions (Zoback and Byerlee, 1975a; Walsh and Brace, 1984; David et al., 1994) and triaxial conditions (VAJDOva et al., 2004) in order to establish effective 
pressure dependency of the permeability. From those studies, the authors have shown a decrease of the permeability with the effective pressure depending on three distinct phases. During the first increments of effective pressure a large reduction of permeability is observed and described by DAvID et al. (1994) as a probable microcracks closure. The rate of permeability reduction decreases at high confining pressure and the authors showed an exponential evolution of the permeability with the effective isostatic pressure. When the effective pressure is further increased, the permeability exhibits a drastic drop at the critical pressure, indicating the onset of inelastic deformation characterized by pore collapse commonly associated with intensive grain crushing (ZHANG et al., 1990a). The average critical pressure is about $200 \mathrm{MPa}$ in sandstones, although it depends essentially on the initial porosity value of tested material. Due to the limitations of our experimental setup, we are not able to reach the pore collapse pressure of the Fontainebleau and Bentheimer sandstone. However, we mostly focus our interest on the first two regimes of permeability reduction mechanisms. In most cases, the pressure dependencies of the permeability have been determined using the overall pressure drop over the complete length of the sample. The results obtained with the additional sampling of pressure drop on the middle length of the sample provide a complementary explanation for the drastic permeability drop occurring at low effective pressure.

\subsection{Evidence of End Effects on Axial Permeability}

The presented results on Bentheimer sandstone show that axial permeabilities measured by the two different methods differed strongly at the beginning of loading. The comparable discrepancy factor has been observed by KoRSNES et al. (2006) under deviatoric stresses on both chalk and sandstone samples. The authors used a modified core sleeve, allowing the measurement of mid-length permeability as in our study; they found a discrepancy factor of 1.2 to 2.4 between the two axial measurements, as we do on the Bentheimer sandstone. They concluded that end effects occurring at the sample/piston interface were responsible for these initial discrepancies.

Conversely to the Bentheimer sandstone, the initial axial permeabilities measured on the Fontainebleau sandstone samples show strictly the same value (according to the estimated error). Because of different microstructures, the two sandstones may exhibit different responses to end effects in terms of permeability damage on the first $3 \mathrm{MPa}$ of loading. Mechanical preparation, such as sample cutting, may also induce some nearsurface damage. Such effects may be more pronounced for the loosely packed Bentheimer sandstone.

In addition, KORSNES et al. (2006) did not report different evolution divergences with increasing pressure; conversely we have observed different trends depending on the measurements method. Indeed, for the three samples subjected to hydrostatic loading, the preliminary nonelastic regime response of the permeability is more pronounced for the full-length measurement (30 to $50 \%$ of the initial value), than for the mid-length measurement (less than $10 \%$ of initial value if it occurred). The porosity response also 
has manifested the same nonlinear evolution in the range of low effective pressure. Furthermore, the porosity of the Bentheimer sandstone showed a hysteresis and the residual value at $3 \mathrm{MPa}$ is $24 \%$. These observations suggest closure of a limited part of the pore volume, however, this mechanism alone cannot explain the discrepancies of the permeabilities evolution. We also suspect end effects to induce higher deformation of the sample at the contact of the pistons. ForTin et al. (2005) have shown that during compression experiments on the Bentheimer sandstone, the acoustic emission relocalization highlighted a compressive damage area close to the interface between the pistons and the sample at an early stage of compression. This early localized compaction could explain pronounced inelastic behavior of the full-length axial permeability, while the mid-length permeability remains unaffected due to the distance of the pressure samplers from the core ends.

\subsection{FEM Modelization of End Effects on Strain Localization}

We have performed FEM computations in order to estimate the effects of boundary conditions and sample geometry on the stress distribution within the sample. The samples are assumed to be homogeneous and to behave as isotropic linear elastic materials.

The ideal test assumes lubrication between piston and sample; in practice the condition is closer to perfect adherence without slip, and this is even more so when there is a groove in the piston head which may indent the sample. The pistons are made of a titanium alloy with a Young's modulus at least ten times larger than the modulus of sandstone $E_{\text {sample }}=10.3 \mathrm{GPa}$ and $E_{\text {pistons }}=114 \mathrm{GPa}$ and also a different Poisson's ratio $v_{\text {sample }}=0.2$ and $v_{\text {pistons }}=0.24$. At the interfaces (top and bottom) between piston and sample, the strain incompatibilities induce local stress gradients. A FEM computation cannot exactly reproduce the experimental end conditions, but allows the check of assumptions which provide bounds to the actual conditions. A mesh of 9-noded quadrilateral elements with initial square sections of $1 \mathrm{~mm}^{2}$ is utilized. The exact dimensions of the cylindrical samples are given and one replaces the actual pistons by two additional cylinders of $20 \mathrm{~mm}$ height and the same diameter. A perfect link is assumed at the two interfaces piston/sample assembly. The behavior remains elastic, and the load is applied by using pressure elements at the top and around the assembly pistonssample. One can thus easily perform the two virtual tests of hydrostatic loading (same pressure, chosen as $10 \mathrm{MPa}$ ) and uniaxial loading with small confining pressure (10 $\mathrm{MPa}$ on top and $3 \mathrm{MPa}$ around).

Figure 9 presents the results of the simulation of both configuration tests with regard to axial, radial, shear and equivalent stress inhomogeneities. The simulation shows that the ends of the sample are regions where high stress gradients appear; in particular, there is a departure from hydrostatic conditions, although the middle of the sample remains under hydrostatic stress state. The axial stress in both loading cases (Figs. 9a and 9f) is larger in magnitude near the interface and also at the outside edges of the samples. Its variation along the sample axis is not uniform but after a region where it remains 

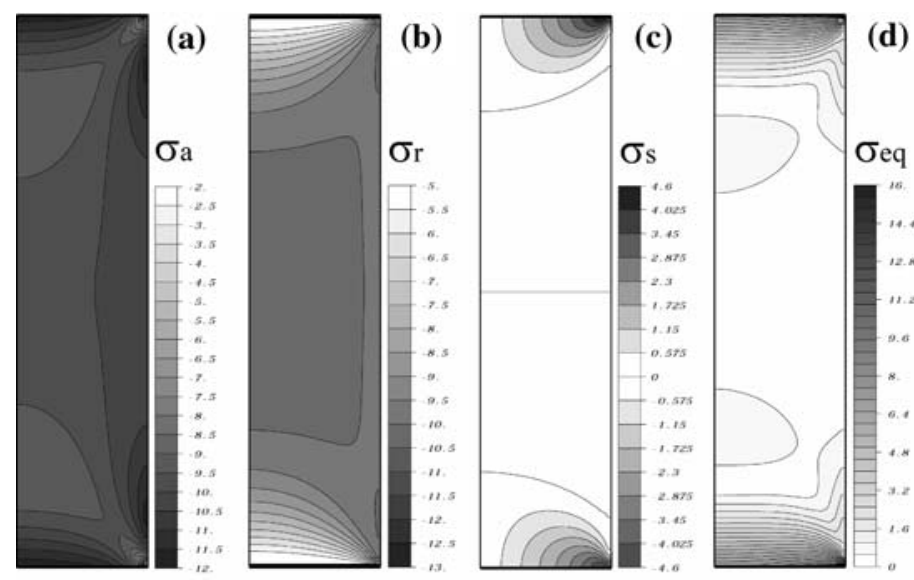

(d)
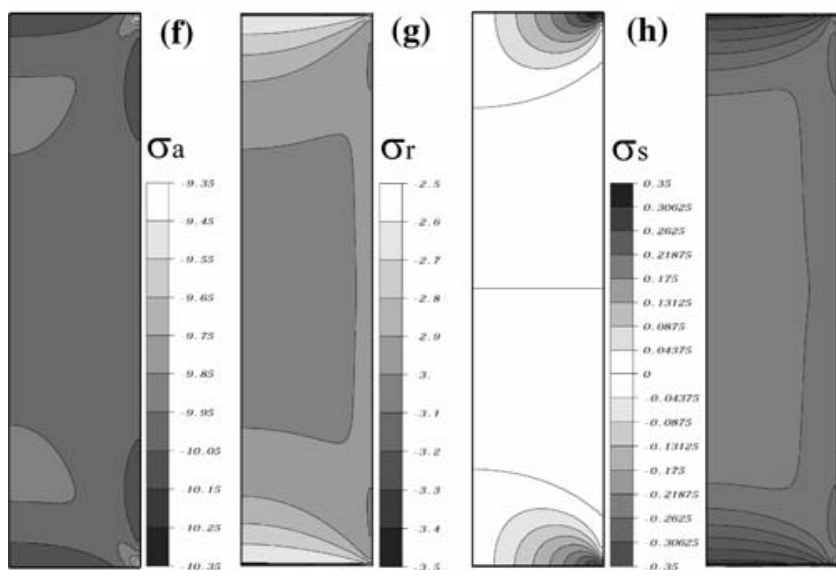

(i)

(e)

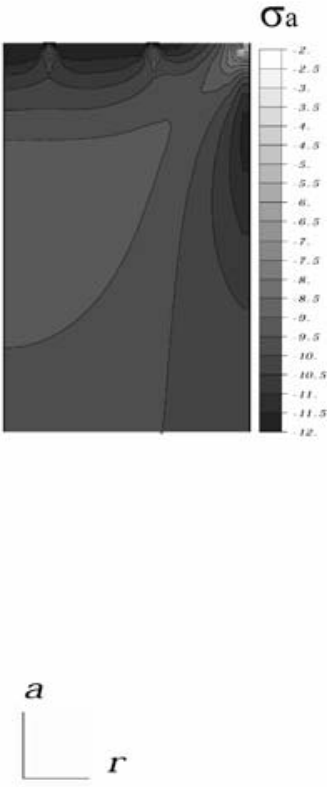

Figure 9

Results of FEM simulation for both hydrostatic at $10 \mathrm{MPa}$ (top) and axial at $10 \mathrm{MPa}$ with low $3 \mathrm{MPa}$ confining pressure (bottom) loading, and representations of the axial (a, f), radial (b, g), shear (c, h) and equivalent (d, i) stress fields within the sample (unit in MPa). (e) Focus on the influence of the grooved piston on the axial stress at the interface between the sample and the upper piston, for the hydrostatic configuration.

constant, it decreases at first and then increases again near the pistons. There is a lensshaped region near each end where the axial stress is slightly smaller than everywhere else. In addition, the radial stress (Figs. $9 \mathrm{~b}$ and $9 \mathrm{~g}$ ) is fairly uniform in the middle region and compressive. It is however rapidly varying very near the interfaces and a shear stress also develops at the interfaces, more pronounced in the hydrostatic case (Fig. 9c). In the grooved pistons case (Fig. 9e) there is no evidence of a larger zone of heterogeneity than in the simple configuration. The effect remains local but induces a larger perturbation of the isocontours of stresses.

Keeping in mind the strong assumptions of homogeneity and purely elastic behavior, it remains to check whether these computed variations are responsible for early damage 
of the samples. Indeed, the simulations exhibit a high inhomogeneity of the stress states near the sample ends, especially during the hydrostatic loading. Due to their structural heterogeneities, the sandstones may be very sensitive to this not purely hydrostatic stress field, which could be responsible for stress localization within the grains boundaries and local grain rearrangements near the pistons' contacts. The results of the simulations support the experimental observations, and would explain the high permeability drops observed on the full-length axial permeability.

\subsection{Radial Injection Conditions' Fluctuations during Compression Experiments}

We have showed and simulated how the mechanical response of the samples could generate a strong loss of the axial permeability during the beginning of pressure increase. Similar experimental results indicate end effects on the radial permeability measurements, but these are related to the experimental setup and data retrieval procedure. Firstly, we find a systematic weak discrepancy factor between initial axial and radial permeability values. This factor varies from +1.9 and -1.4 for the FS1 and FS2 samples respectively, and of 1.4 for the Bentheimer sandstone, while Lous et al. (2003) and BEnson et al. (2005) have shown slight permeability anisotropy for the Bentheimer sandstone. This discrepancy is most likely related to the Geometric Factor $G$ introduced in equation (2) to calculate the radial permeability; experimental radial fluid injection could indeed differ from the simple geometry used in our FEM model. Secondly, we have observed an important loss of the radial permeability up to a confining pressure of $10 \mathrm{MPa}$ from $20 \%$ for the Bentheimer sandstone of the initial value to $60 \%$ for the FS2 sample. Those strong evolutions are not observed on the FS1 sample that is subjected to higher initial confining pressure of $6 \mathrm{MPa}$. The important loss of radial permeability could not be explained only by the response of the sandstone sample, but also by an intensive deformation of fiber within the Al316 spacers placed between injectors and sample surface. To understand how the discs are deformed during the compression tests, we have observed the microstructure of as-received and deformed discs by microtomography imaging analysis (see Fig. 10). The undeformed disc exhibits two superposed layers with averaging mesh aperture of $10 \mu \mathrm{m}$ (transect A-B) and $25 \mu \mathrm{m}$ (transect C-D) for an averaging thickness of $600 \mu \mathrm{m}$, whereas the deformed disc is inhomogeneously compacted by up to $200 \mu \mathrm{m}$. The most porous layer is the most intensively strained.

These high deformations of the discs might have reduced drastically their permeabilities and certainly induced important perturbation of the flow conditions at the inlet and the outlet of the injectors. The deformation of the discs could have been more pronounced during the first steps of confining pressure increase, which could explain efficiently the drastic drop of radial permeabilities. The impact of the discs deformations on their permeabilities is very difficult to quantify; we suggest that experimental measurements performed above $10 \mathrm{MPa}$ might be representative of sample behavior. Nevertheless, the discs are needed to perform radial flows; indeed, compression 

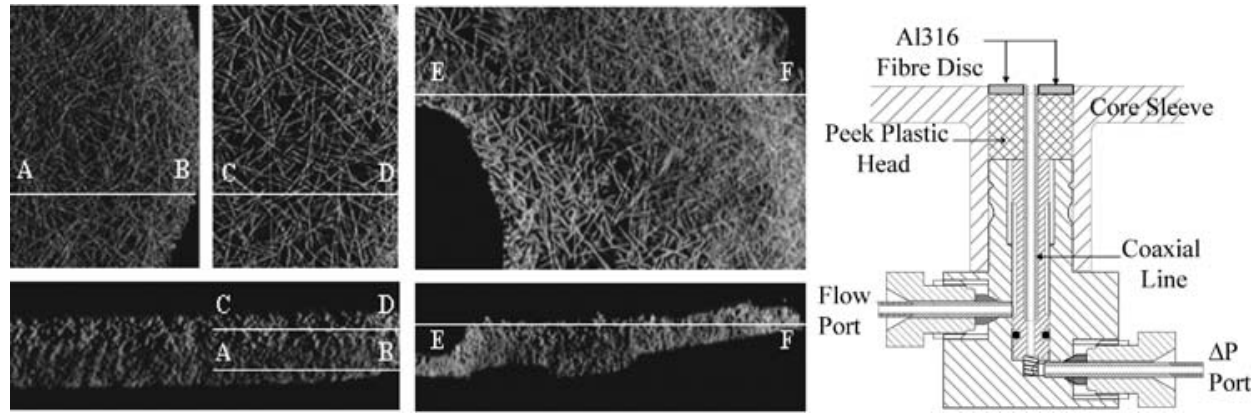

Figure 10

Microtomography slices of Al-316 fiber discs in (left) underformed (0.5 mm thickness) and (center) deformed states; (right) drawing showing the fiber disc position on a radial flow port.

tests performed without the discs lead to clogging of the injectors and the loss of the radial measurements capacity.

\section{Conclusions}

Our first experiments validate a new triaxial cell specifically designed for multidirectional permeability measurements in reservoir rocks under hydrostatic and deviatoric stresses. We have used two types of sandstones covering a wide range of porosity (from 5.8 to $24.4 \%$ ) and permeabilities (from 2.5 to $3000 \mathrm{mD}$ ). Classical axial permeability measurements on Fontainebleau sandstone with our setup are in very good agreement with other experiments and models from the literature.

However, our classical axial (full-length) and radial permeability measurements are very sensitive at the beginning of the hydrostatic loading both for Fontainebleau and Bentheimer sandstones. The evolutions of permeabilities are characterized, in most cases, by an initial strong decrease followed by a slight linear variation. In contrast, the innovative axial mid-length measurements present a more moderate and steady evolution. Our experimental results and FEM simulations suggest stress inhomogeneities (variation in magnitude and triaxiality) in the vicinity of the piston/sample interfaces which may induce local microstuctural evolutions (damage at the grain scale or pore collapse), which in turn might strongly reduce the full-length axial permeability. Such end effects would not affect the mid-length axial permeability measurements, which are what we observe.

Our work clearly shows that hydromechanical end effects can alter significantly the standard permeability measurements using classical permeameter, even on consolidated rocks, like sandstones, thought to be less sensitive. This may lead to erroneous micromechanical interpretation of permeability reduction and also to an overestimation of the permeability decrease with overburden stress or effective stress evolution, potentially critical for field case developments. Experimental data of pressure dependent 
permeability, reported in the literature, should therefore be considered with care. Recent experiments performed on carbonates showed less pronounced end effects, suggesting mineralogical and/or microstructural influences.

As for the radial permeability evolutions, we have clearly observed, after loading, microstructural evolutions of the Al316 spacers inserted between the sample and the flow lines that could explain the initial loss of radial permeability.

Additional uniaxial loading experiments do confirm the influence of shear-band formation on radial permeability which is strongly reduced owing to grain crushing and densification within the shear band. These motivating results show the interest of directional measurements during a single loading experiment to investigate more efficiently the influence of high deformation on generated anisotropy. With regards to the pressure limit of our experimental setup $(69 \mathrm{MPa})$ and the high strength of sandstone samples, we are only able to investigate the influence of the brittle failure regime on the permeability evolution. Nevertheless, preliminary experiments performed on soft carbonates reach higher deformation regimes, such as the shear-enhanced compaction regime, and provide a new set of data with which to understand the influence of stress paths on permeability anisotropy evolutions.

\section{Acknowledgements}

The authors thank Eric Ferne at I.F.P. and Serge Chanchole at L.M.S. for valuable technical assistance with the directional flow triaxial setup. We also are grateful to Elisabeth Bemer for helpful suggestions on the geomechanical aspects of this work. We extend thanks to Daniel Caldemaison for access to SEM at L.M.S., to Elisabeth Rosenberg and Souhail Youssef for microtomography acquisition and volume reconstruction at I.F.P. The support of Olga Vizika and Jean-Marc Lombard in this project is also acknowledged.

\section{REFERENCES}

Al-Harty, S.S., Jing, X.D., Marsden, J.R., and Dennis, J.W. (1999), Petrophysical properties of sandstones under true triaxial stresses I: Directional transport characteristics and pore volume change, SPE 57287.

BaI, M., Meng, F., Roegiers, J.C., and Green, S. (2002), Improved determination of stress-dependent permeability for anisotropic formations, SPE 78188.

Benson, P.M., Meredith, P.G., Platzman, E.S., and White, R.E. (2005), Pore fabric shape anisotropy in porous sandstones and its relation to elastic wave velocity and permeability anisotropy under hydrostatic pressure, Int. J. Rock. Mech. 42, 890-899.

Bourbie, T. and Zinszner, B. (1985), Hydraulic and acoustic properties as a function of porosity in Fontainebleau sandstone, J. Geophys. Res. 90, 11524-11532.

BRUnO, M.S. (1994), Micromechanics of stress-induced permeability anisotropy and damage in sedimentary rock, Mech. of Mat. 18, 31-48.

Clavaud, J.-B., Maineult, A., Zamora, M., Rasolofosoan, P., and Schlitter, C. (2008), Permeability anisotropy and its relations with porous medium structure, J. Geophys. Res. 113, B01202. 
Collins, R.E., Flow of Fluids through Porous Materials (Reinhold Publishing Co., New York. 1961).

Dautriat, J., Gland, N., Youssef, S., Rosenberg, E., Bekri, S., and Vizika, O. (2009), Stress-dependent directional permeabilities of two analog reservoir rocks: A prospective study on contribution of $\mu$-tomography and pore network models, SPE Res. Eval. Eng. (in press).

David, C., Wong, T.F., Zhu, W., and Zhang, J. (1994), Laboratory measurements of compaction-induced permeability change in porous rock: Implications for the generation and maintenance of pore pressure excess in the crust, Pure Appl. Geophys. 143, 425-456.

Fortin, J., Schubnel, A., and Gueguen, Y. (2005), Elastic wave velocities and permeability evolution during compaction of Bleurswiller sandstone, Int. J. Rock Mech. and Min. Sci. 42, 873-889.

FourIE, A.B. and XIAOBI, D. (1991), Advantages of midheight measurements in undrained triaxial testing, ASTM Geotech. Test. J. 14, 138-145.

Grisoni, J.C. and ThIRY, M. (1988), Répartition des grès dans les sables de Fontainebleau: implications géotechniques des études récentes, Bull. Liaison Labo P. et Ch. 157, Réf. 3333.

HEILAND, J. and RAAB, S. (2000), Experimental investigation of the influence of differential stress on permeability of a Lower Permian (Rotliegend) sandstone deformed in the brittle deformation field, Phys. Chem. Earth (A) 26, 33-38.

HeIland, J. (2003), Laboratory testing of coupled hydro-mechanical processes during rock deformation, Hydrogeol. J. 11, 122-141.

Holt, R.M. (1990), Permeability reduction induced by a non-hydrostatic stress field, SPE Form. Eval. 5, 444 448.

Klein, E. and Reutschlé, T. (2003), A model for the mechanical behaviour of Bentheim sandstone in the brittle regime, Pure Appl. Geophys. 160, 833-849.

Korsnes, R.I., Risnes, R., FaldaAs, I., and Norland, T. (2006), End effects on stress dependent permeability measurements, Tectonophys. 426, 239-251.

LEE, K.L. (1978), End restraint effects on undrained static triaxial strength of sand, J. Geotech. Eng. Div. 104, 687-704.

Louis, L., DAvid, C., and RoBion, P. (2003), Comparison of the anisotropic behaviour of undeformed sandstones under dry ad saturated conditions, Tectonophys. 370, 193-212.

Morita, N., Gray, K., Srouji, F.A.A., and Jogi, P.N. (1984), Rock property changes during reservoir compaction, SPE 13099.

Morrow, C.A., Bo-Chong, Z., and Byerlee, J.D. (1984), Effective pressure law for permeability of Westerley Granite under cyclic loading, J. Geophys. Res. 91, 3870-3876.

RhetT, D.W. and Teufel, L.W., Stress path dependence of matrix permeability of North Sea sandstone reservoir rock. In Rock Mechanics (ed. Tillerson and Wawersik) (Balkema, Rotterdam 1992a) pp. 345-353.

Rhett, D.W. and Teufel, L.W. (1992b), Effect of reservoir stress path on compressibility and permeability of sandstones, SPE 24756.

SchutJens, P.M.T.M. and De RuIG, H. (1997), The influence of stress path on compressibility and permeability of an overpressured reservoir sandstone: Some experimental data, Phys. Chem. Earth. 22, 97-103.

Sheng, D., Westerberg, B., Mattsson, H., and Axelsson, K. (1997), Effects of end restraint and strain rate in triaxial tests, Comp. and Geotech. 21, 163-182.

Sulem, J. and Ouffroukh, H. (2006a), Shear banding in drained and undrained triaxial tests on a saturated sandstone: Porosity and permeability evolution, Int. J. Rock Mech. and Min. Sci. 43, 292-310.

Sulem, J. and Ouffroukh, H. (2006b), Hydromechanical behaviour of Fontainebleau sandstone, Rock Mech. and Rock Eng. 39, 185-213.

Trautwein, U. and Huenges, E. (2005), Poroelastic behaviour of physical properties in Rotliegend sandstones under uniaxial strain, Int. J. Rock Mech. and Min. Sci. 42, 924-932.

Vajdova, V., Baud, P., and Wong, T.-F. (2004), Permeability evolution during localized deformation in Bentheim sandstone, J. Geophys. Res. 109, B10406.

WALSH, J.B. and BRACE, W.F. (1984), The effect of pressure on porosity and the transport properties of rock, J. Geoph. Res. 89, 9425-9431.

Wong, T.-F., David, C., and Zhu, W. (1997), The transition from brittle faulting to cataclastic flow in porous sandstones: Mechanical deformation, J. Geophys. Res. 102, 3009-3026.

Zhang, J., Wong, T.-F., and Davis, D.M. (1990a), Micromechanics of pressure-induced grain crushing in porous rocks, J. Geoph. Res. 95, 341-352. 
ZHu, W. and Wong, T.-F. (1997), The transition from brittle faulting to cataclastic flow: Permeability evolution, J. Geophys. Res. 102, 3027-41.

Zoback, M.D. and Byerlee, J.D. (1975), Permeability and effective stress, Am. Assoc. Petrol. Geol. Bull. 59, $154-158$. 